\title{
Microstructure Formation in Sn-Cu-Ni Solder Alloys*
}

\author{
M. Felberbaum, T. Ventura, M. Rappaz, and A.K. Dahle
}

A systematic study of the solidification mechanisms of binary $\mathrm{Sn}-\mathrm{Cu}$ and ternary $\mathrm{Sn}$-Cu-Ni alloys has been carried out. It is found that $\mathrm{Sn}-\mathrm{Cu}$ is a weakly-irregular eutectic system with $\mathrm{Cu}_{6} \mathrm{Sn}_{5}$ as the leading phase. Interestingly, two different eutectic morphologies (coarse and fine) are found to grow simultaneously during eutectic solidification. When the growth rate or composition are changed, the eutectic interface breaks down into a cellular eutectic with the fine eutectic in the centre of the cells and the coarse one at the cell boundaries. The mechanisms responsible for these phenomena are discussed in conjunction with the beneficial effect of $\mathrm{Ni}$ additions to the $\mathrm{Sn}$-Cu solder.

\section{INTRODUCTION}

For the past 50 years, eutectic and near-eutectic tin-lead $(\mathrm{Sn}-\mathrm{Pb})$ solders have provided an effective solution for joining metallic surfaces in the electronics industry. The low cost and low melting point of the $\mathrm{Pb}-\mathrm{Sn}$ eutectic ( $T_{\text {eut }}$ $=456 \mathrm{~K}$ ) made such alloys particularly suitable for soldering thermally sensitive electronic components. However, due to its high toxicity, lead has been banned from the European Union (EU) market and new electronic equipment must now contain less than $1,000 \mathrm{ppm}$ $\mathrm{Pb}$ (EU Directive 2002/95). For the past decade, this has stimulated the search for an optimum lead-free replacement solder.

Because of the relatively low melting temperature of tin $\left(T_{m}=505 \mathrm{~K}\right)$, Sn-rich alloys are good candidates for lead-free solders. A hypoeutectic alloy with a short freezing range is generally chosen, because (i) a hypereutectic composition is detrimental for soldering properties since the primary inter- metallic phase can form short circuits and (ii) a reduced solidification interval decreases the chance of defects formation such as hot tears. In that prospect, copper $(\mathrm{Cu})$ is often used as an alloy-

\section{How would you...}

...describe the overall significance of this paper?

Lead is undesirable in solders

because of its high toxicity.

Accordingly, tin-copper and

tin-copper-nickel alloys have

주

been suggested as candidates to replace lead-containing solders.

$\nabla$

Understanding the solidification mechanisms of these alloys is essential in order to find the optimal operating window for their industrial use and this paper is aimed at doing

$\rightarrow$

...describe this work to a

$\exists$

\section{.} materials science and engineering professional with no experience in your technical specialty?

This study focuses on the microstructure formation in neareutectic tin-copper and tin-coppernickel solder alloys. Different

- types of microstructures were obtained by systematically varying the alloy composition and/or solidification velocity in a Bridgman furnace. Each result is explained

- using conventional solidification mechanisms and the beneficial effect of nickel additions to the tin-copper solder is discussed.

...describe this work to a layperson?

Lead-containing solders have been extensively used in the past been extensively used in their low cost and good solderability. However the use of lead-based solders is now banned because of lead's high toxicity and tin-copper alloys are good candidates for replacing them. Moreover, small additions of nickel significantly improve the solderability of tin-copper alloys and this paper is aimed at explaining why and how. ing element and the composition Sn$0.7 \mathrm{wt} . \% \mathrm{Cu}$ is of particular interest. Not only having good soldering properties and cost advantages compared to $\mathrm{Ag}$ containing solder alloys, ${ }^{1}$ this alloy exhibits soldering properties that can be significantly improved by small additions of nickel (Ni)., ${ }^{2,3}$ Although Sn$\mathrm{Cu}-\mathrm{Ni}$ alloys are already commercially in use, their solidification mechanisms remain unclear and the influence of $\mathrm{Ni}$ on the binary $\mathrm{Sn}-0.7 \mathrm{Cu}$ alloy also needs to be further understood (unless otherwise specified, all compositions are given in wt.\%).

Using Bridgman solidification experiments, we have recently investigated the solidification mechanisms of Sn-rich Sn-Cu-Ni alloys and identified several mechanisms responsible for the beneficial effect of $\mathrm{Ni}$ in the $\mathrm{Sn}-0.7 \mathrm{Cu}$ solder. ${ }^{4,5}$ This paper gives an overview on the progress in understanding microstructure formation in this new solder.

\section{BINARY SN-CU ALLOYS}

The main results for the binary $\mathrm{Sn}$ $\mathrm{Cu}$ alloys are summarized in Figure 1, which shows the influence of growth velocity and $\mathrm{Cu}$ content on the microstructure. For relatively high growth velocities and $\mathrm{Cu}$ contents less than 0.9 wt. $\%$, a microstructure consisting of primary $\beta$-Sn cells or dendrites surrounded by eutectic ( $\beta-\mathrm{Sn}+$ intermetallic $\mathrm{Cu}_{6} \mathrm{Sn}_{5}$ ) was obtained (see Figure 1a). On the other hand, a fully eutectic microstructure was obtained in the cases of: i) low growth velocities, independent of $\mathrm{Cu}$ content (see Figure 1b) and ii) a fixed composition of $\mathrm{Sn}-0.9 \mathrm{Cu}$, independent of growth velocity (see Figure 1c). Thus, a transition from off-eutectic to fully eutectic microstructure is observed to occur in 
the hypoeutectic alloy when the pulling speed is increased. This is a classical transition in solidification science and is caused by the competition in growth kinetics between $\beta$-tin dendrites (or cells) and the eutectic. ${ }^{6}$

Focusing now on the eutectic morphology, Figure 2a shows a longitudinal cross-section of a $\mathrm{Sn}-0.7 \mathrm{Cu}$ alloy grown at $2 \mu \mathrm{m} / \mathrm{s}$. Although the eutectic interface seems planar at this magnification, it is not strictly isothermal at higher magnification, with $\mathrm{Cu}_{6} \mathrm{Sn}_{5}$ fibers growing slightly ahead of the $\mathrm{Sn}$ matrix. ${ }^{4}$ In Figure 2b, the eutectic interface is much more irregular in Sn$0.7 \mathrm{Cu}-0.03 \mathrm{Ni}$ grown at $10 \mu \mathrm{m} / \mathrm{s}$. The eutectic interface contains perturbations on the order of $50 \mu \mathrm{m}(\sim 0.12 \mathrm{~K})$, which is a typical characteristic of a weakly irregular eutectic, i.e., where the faceted $\mathrm{Cu}_{6} \mathrm{Sn}_{5}$ intermetallic phase is only slightly branched. Returning to the phase diagram shown in Figure 1, this suggests that the coupled zone is not much biased towards the faceted $\mathrm{Cu}_{6} \mathrm{Sn}_{5}$ phase. Hence, for any growth velocity, no primary $\beta-\mathrm{Sn}$ dendrites should form at the eutectic composition. While there is some ambiguity regarding the eutectic composition in the $\mathrm{Sn}-\mathrm{Cu}$ system in the literature, our work clearly shows that $\mathrm{Sn}-0.9 \mathrm{Cu}$ is the eutectic composition since a fully eutectic microstructure was found for all growth velocities only at this composition. These results are also in good agreement with the work by Machida et al. on near-eutectic Sn-Cu alloys ${ }^{7}$ (although a higher thermal gradient was used in their case $(G=4.7 \mathrm{~K} / \mathrm{mm}))$. To complete the coupled zone in Figure 1, the dashed line separating the fully eutectic microstructure from the primary $\mathrm{Cu}_{6} \mathrm{Sn}_{5}+$ eutectic structure has been drawn based on the data of Machida et al. ${ }^{7}$

Another interesting eutectic microstructure transition can be observed by comparing the micrographs in Figure $1 \mathrm{~b}$ and Figure 1c: a fully eutectic structure was obtained at low growth velocities, whereas cellular eutectic structures were produced as the growth rate was increased. This morphology change can be explained by the segregation of trace impurities, particularly $\mathrm{Pb}$. Indeed, the destabilization velocity of a tin front (the eutectic front con-

\section{EXPERIMENTAL PROCEDURE}

The research was conducted in three steps: firstly, the solidification mechanisms in the binary Sn-Cu alloy were investigated; secondly, the effect of Ni was considered; and thirdly, an ultrapure $\mathrm{Sn}-0.9 \mathrm{Cu}$ alloy was cast in order to investigate the individual effects of common trace impurities present in commercial $\mathrm{Sn}-\mathrm{Cu}$ alloys (typically $\mathrm{Ag}$ and $\mathrm{Pb}$ ).

Accordingly, three binary $\mathrm{Sn}-\mathrm{Cu}$ alloys $(\mathrm{Sn}-0.5 \mathrm{Cu}, \mathrm{Sn}-0.7 \mathrm{Cu}$, and $\mathrm{Sn}-0.9 \mathrm{Cu})$ were solidified in a classical Bridgman furnace (see Reference 4 for details). The samples were drawn at a given constant velocity $(v=2,5,10,20,50$, or $100 \mu \mathrm{m} / \mathrm{s})$ in a $1 \mathrm{D}$ temperature gradient $(G)$ of about $2.5 \mathrm{~K} / \mathrm{mm}$. After about $60 \mathrm{~mm}$ of growth, the specimens were quenched into cold water to freeze the microstructure. Conventional grinding/polishing was performed to prepare samples for optical and electron microscopy (scanning electron microscopy and transmission electron microscopy) coupled with chemical analysis (energy dispersive spectroscopy). The same experimental procedure was then followed to investigate the effect of $\mathrm{Ni}$ in a $\mathrm{Sn}-0.7 \mathrm{Cu}-x \mathrm{Ni}$ alloy $(x=0.03,0.05,0.08$, and 0.1$){ }^{5}$ Finally, an ultrapure $\mathrm{Sn}-0.9 \mathrm{Cu}$ alloy, contained in a conical cup of about $17 \mathrm{~cm}^{3}$, was solidified in air (typical cooling rate of $0.5 \mathrm{~K} / \mathrm{s}$ ). The effects of separate additions of elemental powders of $\mathrm{Pb}(300 \mathrm{ppm})$ and $\mathrm{Ag}(10 \mathrm{ppm})$ were studied. ${ }^{5}$

sists of $97 \%$ tin) due to $\mathrm{Pb}$ segregation theoretically occurs for the given solidification conditions between 10 and $20 \mu \mathrm{m} / \mathrm{s}$, which coincides with the experimental results. These observations are further confirmed by casting experiments of ultrapure $\mathrm{Sn}-0.9 \mathrm{Cu}$ and $\mathrm{Sn}-0.9 \mathrm{Cu}-0.03 \mathrm{~Pb}$ alloys. ${ }^{5}$ A very fine eutectic morphology was found in the $\mathrm{Sn}-0.9 \mathrm{Cu}$ alloy, whereas a cellular bimodal eutectic structure similar to the one shown in Figure 1c formed in the $\mathrm{Sn}-0.9 \mathrm{Cu}-0.03 \mathrm{~Pb}$ alloy. This is similar to the observations by Kraft and Albright ${ }^{8}$ who found that when the growth rate is very high or the thermal gradient in the liquid at the growing interface is very low, a layer of constitutionally supercooled liquid formed by solute rejection induces a cellular rather than a planar interface of the $\mathrm{Al}_{-} \mathrm{Al}_{2} \mathrm{Cu}$ eutectic. On the other hand, trace level additions of $\mathrm{Ag}$ to ultrapure $\mathrm{Sn}-0.9 \mathrm{Cu}$ resulted in the formation of fine primary $\beta$-Sn dendrites, ${ }^{5}$ suggesting that $\mathrm{Ag}$ could be a potential grain refiner for Sn. However, a separate study refuted this theory and showed that Ag seems to simply stabilize the $\beta$-Sn phase field in the phase diagram without refining the microstructure. ${ }^{9}$

Focusing on Figure 1b, it can be observed that the eutectic morphology is not uniform and can be either fine or coarse. Two separate domains are clearly distinguished, one with a very fine fiber spacing $(\lambda)$ and the other with a much coarser morphology. This is very unusual, especially in a specimen of constant composition and grown at steady-state. Even more surprising, both morphologies have been found to be stable for a range of growth velocities and with each morphology following the classical $\lambda^{2} v=$ constant relationship. This bimodal eutectic structure was previously reported by Drevet et al. ${ }^{10,11}$ who showed that, for both morphologies, the $\mathrm{Cu}_{6} \mathrm{Sn}_{5}$ fibers grow with the basal plane of their hexagonal structure parallel to the eutectic front. Preliminary electron backscatter diffraction (EBSD) results suggest that the orientation of the Sn matrix plays a significant role in the eutectic morphology, but the mechanisms remain unclear.

\section{THE EFFECT OF Ni}

The effect of Ni additions was studied in the $\mathrm{Sn}-0.7 \mathrm{Cu}$ system for several reasons: (i) it would include the composition of the commercial solder SN100C, , (ii) it is important to start with a hypoeutectic alloy (but close to the binary eutectic composition), since in electronics, the coarse primary $\mathrm{Cu}_{6} \mathrm{Sn}_{5}$ particles must be avoided as they can form bridges and short circuits during the wave soldering process, and (iii) comparisons with the binary system $\mathrm{Sn}-\mathrm{Cu}$ can be made.

The results are summarized in Figure 3 where four separate regions (denoted I to IV) are differentiated. Regions I and IV correspond to offeutectic regions where $\beta$-Sn dendrites (or cells) and primary $\mathrm{Cu}_{6} \mathrm{Sn}_{5}$ were observed, respectively. Clearly, no primary phase $\beta$-Sn was obtained for any Ni-containing alloy which shows that $\mathrm{Ni}$ appears to suppress the formation of $\beta$-Sn dendrites in favor of a eutectic microstructure (which is beneficial in 
term of soldering). On the other hand, a eutectic microstructure was obtained in regions II and III, where intermixed coarse and fine eutectics and a cellular eutectic morphology were observed, respectively. This transition is similar to that observed in the $\mathrm{Sn}-\mathrm{Cu}$ system (see microstructures (b) and (c) in Figure 1) and is due to segregation of trace elements, particularly $\mathrm{Pb}$, ahead of the eutectic interface. The transition occurred at the same growth rate as in the binary $\mathrm{Sn}-\mathrm{Cu}$ system and was not influenced by the Ni level. This was expected since $\mathrm{Ni}$ is known to be strongly segregated by $\mathrm{Sn}$ and highly soluble in $\mathrm{Cu}_{6} \mathrm{Sn}_{5}$ to form $(\mathrm{Cu}, \mathrm{Ni})_{6} \mathrm{Sn}_{5}{ }^{12}$

Figure 3 shows that $\mathrm{Ni}$ has a strong influence on the microstructure of Sn$0.7 \mathrm{Cu}-x \mathrm{Ni}$ alloys. For example, for a growth rate of $10 \mu \mathrm{m} / \mathrm{s}$, a transition from hypoeutectic (Figure 3a) $\rightarrow$ fully eutectic (Figure 3b) $\rightarrow$ hypereutectic microstructure (Figure 3c) is observed as the Ni content is increased. Again, this can be explained by the coupled zone concept. The dashed lines in the figure show the coupled zone for the ternary system and suggest that the coupled zone is strongly biased towards the faceted phase, i.e., much more than in the Sn-Cu binary system. Indeed, the eutectic interface becomes much more non-isothermal when $\mathrm{Ni}$ is added to binary $\mathrm{Sn}-\mathrm{Cu}$ alloys, ${ }^{4,5}$ suggesting a more faceted intermetallic phase (compare both microstructures in Figure 2). This is probably due to the influence of $\mathrm{Ni}$ on the solid-liquid interfacial energy, which could transform the weakly irregular $\mathrm{Sn}-\mathrm{Cu}$ eutectic into a strongly irregular eutectic in the ternary alloys.

Interestingly, the $\mathrm{Sn}-0.7 \mathrm{Cu}-0.03 \mathrm{Ni}$ alloy was the only alloy that exhibited a fully eutectic morphology across the range of velocities investigated, indicating that the eutectic valley is located at, or near, this composition. The $\mathrm{Sn}$-rich corner of the $\mathrm{Sn}-\mathrm{Cu}-\mathrm{Ni}$ phase diagram is still under discussion in the literature, and the composition found here appears quite low compared to the phase diagram given in Reference 13 , but is in better agreement with the phase diagram given in Reference 12 , where there is a eutectic valley between the $\beta$-Sn phase field and the $(\mathrm{Cu}, \mathrm{Ni})_{6} \mathrm{Sn}_{5}$ phase field at about 200 ppm Ni. Additionally, fluidity studies

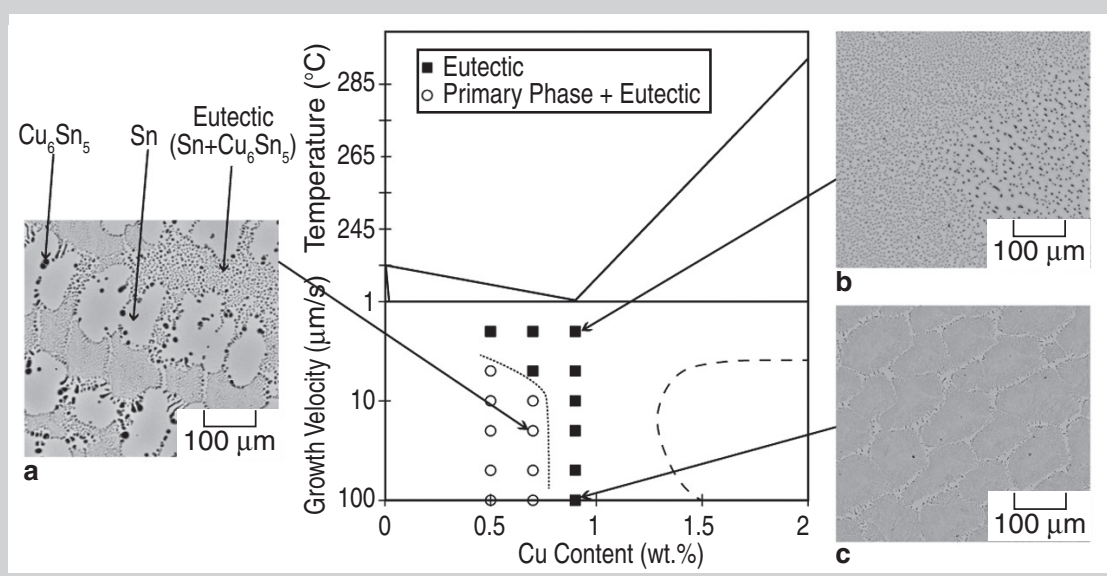

Figure 1. Sn-Cu phase diagram and influence of solidification kinetics on microstructure selection. Each micrograph shows a cross-section from a Bridgman sample (i.e., with $G$ and $v$ perpendicular to the image) at a certain velocity and composition. The dotted line delimits the coupled zone where fully eutectic microstructures were obtained. The dashed line delimits the region of stability of $\mathrm{Cu}_{6} \mathrm{Sn}_{5}+$ eutectic, which is plotted based on the results given in Reference 7.

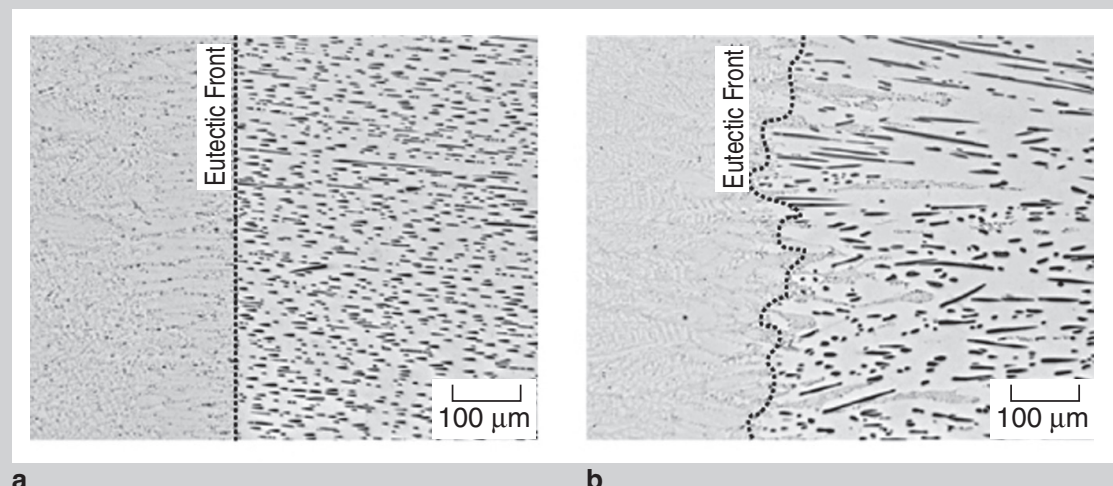

a

b

Figure 2. Solid-liquid interface in fully eutectic specimens. (a) Nearly planar front morphology in Sn-0.7Cu grown at $2 \mu \mathrm{m} / \mathrm{s}$, (b) Non-planar solid-liquid interface in Sn-0.7Cu-0.03Ni grown at $10 \mu \mathrm{m} / \mathrm{s}$.

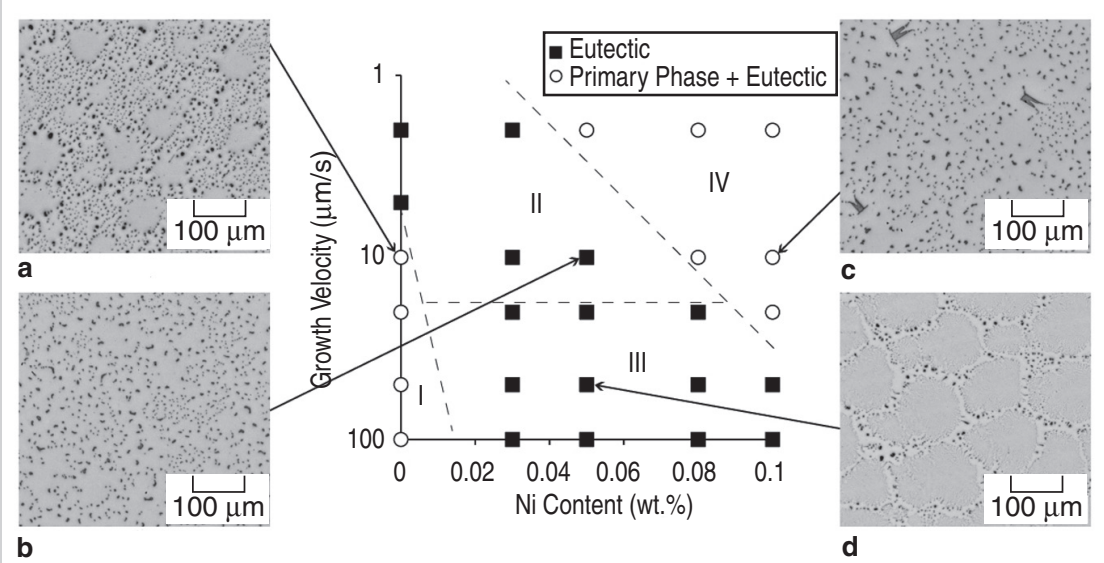

Figure 3. Solidification microstructures observed in $\mathrm{Sn}-0.7 \mathrm{Cu}-x \mathrm{Ni}$ alloys as a function of $\mathrm{Ni}$ content and growth velocity. Each micrograph shows a cross-section from a Bridgman sample (i.e., with $G$ and $v$ perpendicular to the figure) for a certain combination of velocity and composition.

have shown that the maximum fluidity length is achieved with an alloy containing $500 \mathrm{ppm} \mathrm{Ni} .{ }^{14}$ Since alloys with a long fluidity length are related to short freezing range alloys, i.e., fully eutectic alloys, this result suggests that the eutectic composition is close to
Sn- $0.7 \mathrm{Cu}-0.05 \mathrm{Ni}$. The ternary exact eutectic composition is therefore still debated.

As for the binary eutectic alloy, a transition from a fully eutectic (Figure $3 b)$ to a cellular eutectic microstructure (Figure 3c) occurs in all Ni-containing 
alloys at $v \approx 20 \mu \mathrm{m} / \mathrm{s}$. Once again this transition can be attributed to the segregation of ppm levels of $\mathrm{Pb}$ and is not influenced by the Ni level since this element is segregated from the $\beta$-Sn into the $(\mathrm{Cu}, \mathrm{Ni})_{6} \mathrm{Sn}_{5}$ intermetallic. What remains unclear, however, is the coexistence of two scales of the eutectic microstructure, obeying the classical relationship $\lambda^{2} v=$ constant if an average value of $\lambda$ is assumed. In Figure $3 b$ for instance, regions with small $\lambda$ are separated by regions where the eutectic microstructure is much coarser. This is even more pronounced at high $\mathrm{Ni}$ content (see Figure 3d), suggesting that $\mathrm{Ni}$ strongly influences the interfacial energies of the eutectic phases. However, as opposed to the binary alloy, it is very unlikely here that the orientation of the $\beta$-Sn matrix is responsible for this change in eutectic morphology. To clarify this question, a TEM study was performed on both fine and coarse intermetallics in $\mathrm{Sn}-0.9 \mathrm{Cu}$ and $\mathrm{Sn}-0.7 \mathrm{Cu}-$ $0.08 \mathrm{Ni}$ alloys. ${ }^{15}$ Both fine and coarse intermetallics in the binary alloy were identified as monoclinic $\eta^{\prime}-\mathrm{Cu}_{6} \mathrm{Sn}_{5}$, as predicted by Shim et al. ${ }^{16}$ However, the ternary alloy is different: the fine intermetallic was identified as monoclinic $\eta^{\prime}-\mathrm{Cu}_{6} \mathrm{Sn}_{5}$ with a $\mathrm{Ni}$ content of about 8 at.\%, but a new and unknown cubic structure was found in the coarse intermetallic. ${ }^{15}$ Moreover, the center of the coarse intermetallic contains more Ni (about 12 at.\%), whereas the outer edges are $\mathrm{Ni}$-free. In both cases, no trace of Ni was found in the $\beta$-Sn matrix. This suggests that the coarse intermetallic is metastable while the fine eutectic is the stable phase in $\mathrm{Ni}$ - containing $\mathrm{Sn}-\mathrm{Cu}$ solder. It is thought that coarsening experiments might bring some further insight into these questions.

\section{CONCLUSIONS}

This study focused on the microstructure formation in near-eutectic Sn$\mathrm{Cu}$ and $\mathrm{Sn}-0.7 \mathrm{Cu}-x \mathrm{Ni}$ alloys. For both the binary and ternary systems, a transition from fully eutectic to off-eutectic microstructure with increasing growth velocity was explained by the coupled zone concept. The eutectic was identified as weakly irregular in the binary system and strongly irregular in the ternary alloys, probably due to the influence of $\mathrm{Ni}$ on the interfacial energy of the eutectic phases. Consequently, the coupled zone is thought to be slightly and strongly biased toward the faceted intermetallic phase in the binary and ternary system, respectively. In both systems, a transition from fully eutectic to cellular eutectic structures was observed as the growth velocity was increased. It was found that this change in morphology is due to the segregation of impurity elements, particularly $\mathrm{Pb}$, and is not affected by the Ni content, as the latter element is strongly soluble in the intermetallic phase. In terms of solderability, it is thought that Ni additions to $\mathrm{Sn}-0.7 \mathrm{Cu}$ shift the hypoeutectic binary composition to a near ternary eutectic, which improves the fluidity and reduces the freezing range. The influence of $\mathrm{Ni}$ on the interfacial energy of the different phases is also probably beneficial in terms of wettability (as observed commercially) and further studies are required to confirm this sug- gestion.

\section{ACKNOWLEDGEMENTS}

The authors would like to thank Mr. Tetsuro Nishimura, Nihon Superior Co. Ltd., Japan, for his support to this project.

\section{References}

1. C.M.L. Wu, D.Q. Yu, C.M.T. Law, and L. Wang, J. Electronic Mater., 31 (2002), pp. 928-932.

2. T. Nishimura, U.S. patent $6,180,055$ B1 (Nihon Superior Sha Co. Ltd., 1999).

3. T. Nishimura, S. Suenaga, and M. Ikeda, PRICM 4, 6 (2001), pp. 1087-1090.

4. T.Ventura, S. Terzi, M. Rappaz, and A. K. Dahle, Acta Materialia, 59 (2011), pp. 1651-1658.

5. T. Ventura, S. Terzi, M. Rappaz, and A. K. Dahle, Acta Materialia, to be published (2011).

6. W. Kurz and D.J. Fisher, International Metals Reviews, 24 (1979), pp. 177-204.

7. J. Machida, H. Esaka, M. Tamura, and K. Shinozuka, J. Jpn. Inst. of Metals, 70 (2006), pp. 73-79.

8. R.W. Kraft and D.L. Albright, Transactions of the Metallurgical Society of AIME 221 (1961), pp. 95-102. 9. T. Ventura, M. Rappaz, and A.K. Dahle (submitted to publication). Name of publication?

10. B. Drevet, D. Camel, M. Dupuy, and J.J. Favier, Acta Materialia, 44 (1996), pp. 4071-4084.

11. B. Drevet, J.P. Garandet, D. Camel, and J.J. Favier, J. Crystal Growth, 129 (1993), pp. 549-558.

12. V. Vuorinen, H. Yu, T. Laurila, and J.K. Kivilahti, J. Electron. Mater., 37 (2008), pp. 792-805.

13. C.R. Lin, S.W. Chen, and C.H. Wang, J. Electron. Mater., 31 (2002), pp. 907-915.

14. T.Ventura, C.M. Gourlay, K. Nogita, T. Nishimura, M. Rappaz, and A.K. Dahle, J. Electron. Mater., 37 (2008), pp. $32-39$ (2008)

15. T. Ventura, Y. H. Cho, C. Kong and A. K. Dahle, J. Electron. Mater., 40 (2001), pp. 1403-1408.

16. J.H. Shim, C.S. Oh, B.J. Lee, and D.N. Lee, Zeitschrift Fur Metallkunde, 87 (1996), pp. 205-212.

M. Felberbaum, T. Ventura, and A.K. Dahle are with the Department of Materials Engineering, University of Queensland, Brisbane, Qld. 4072, Australia; M. Rappaz is with the Computational Materials Laboratory, Ecole Polytechnique Fédérale Lausanne, 1015 Lausanne, Switzerland. 